\title{
Colchicine Use Is Associated with Decreased Prevalence of Myocardial Infarction in Patients with Gout
}

\author{
DARIA B. CRITTENDEN, R. AARON LEHMANN, LAURA SCHNECK, ROBERT T. KEENAN, BINITA SHAH, \\ JEFFREY D. GREENBERG, BRUCE N. CRONSTEIN, STEVEN P. SEDLIS, and MICHAEL H. PILLINGER
}

\begin{abstract}
Objective. The ability of antiinflammatory strategies to alter cardiovascular risk has not been rigorously examined. Colchicine is an antiinflammatory agent that affects macrophages, neutrophils, and endothelial cells, all of which are implicated in the pathogenesis of cardiovascular disease. We examined whether colchicine use was associated with a reduced risk of myocardial infarction (MI) in patients with gout.

Methods. We conducted a retrospective, cross-sectional study of all patients with an International Classification of Diseases, 9th ed, code for gout in the electronic medical record (EMR) of the New York Harbor Healthcare System Veterans Affairs network and $\geq 1$ hospital visit between August 2007 and August 2008. Hospital pharmacy data were used to identify patients who had filled at least 1 colchicine prescription versus those who had not. Demographics and CV comorbidities were collected by EMR review. The primary outcome was diagnosis of MI. Secondary outcomes included all-cause mortality and C-reactive protein (CRP) level.

Results. In total, 1288 gout patients were identified. Colchicine $(\mathrm{n}=576)$ and no colchicine $(\mathrm{n}=712)$ groups had similar baseline demographics and serum urate levels. Prevalence of MI was $1.2 \%$ in the colchicine versus $2.6 \%$ in the no-colchicine group $(\mathrm{p}=0.03)$. Colchicine users also had fewer deaths and lower CRP levels, although these did not achieve statistical significance. Colchicine effects persisted when allopurinol users were excluded from the analysis.

Conclusion. In this hypothesis-generating study, gout patients who took colchicine had a significantly lower prevalence of MI and exhibited trends toward reduced all-cause mortality and lower CRP level versus those who did not take colchicine. (First Release June 1 2012; J Rheumatol 2012;39:1458-64; doi:10.3899/jrheum.111533)
\end{abstract}

Key Indexing Terms:

GOUT

COLCHICINE

MORTALITY

\section{MYOCARDIAL INFARCTION C-REACTIVE PROTEIN}

From the Crystal Diseases Study Group, Division of Rheumatology and Division of Cardiology, New York University School of Medicine, New York, New York; Department of Medicine, New York Harbor Healthcare System, New York Campus, U.S. Department of Veterans Affairs, New York, NY; and Division of Rheumatology, Duke University Medical Center, Durham, North Carolina, USA.

Drs. Keenan and Lehmann were supported by US National Institutes of Health T32 training grant 5T32AR007176.

D.B. Crittenden, MD, Chief Rheumatology Fellow; R.A. Lehmann, MD, Rheumatology Fellow; L. Schneck, Research Volunteer, NYU School of Medicine; R.T. Keenan, MD, MPH, Assistant Professor of Medicine, Duke University School of Medicine; B. Shah, MD, Instructor of Medicine; J.D. Greenberg, MD, MPH, Assistant Professor of Medicine;

B.N. Cronstein, MD, Paul R. Esserman Professor of Medicine, Pathology and Pharmacology, Director, NYU Clinical and Translational Science Institute, NYU School of Medicine; S.P. Sedlis, MD, Associate Professor of Medicine, Director of Interventional Cardiology, New York Harbor VA Healthcare System, New York Campus; M.H. Pillinger, MD, Associate Professor of Medicine and Pharmacology, NYU School of Medicine, Section Chief of Rheumatology, New York Harbor VA Healthcare System, New York Campus.

Dr. Crittenden and Dr. Lehmann served as co-first authors and contributed equally to this report.

Address correspondence to Dr. D.B. Crittenden, Division of

Rheumatology, NYU Hospital for Joint Diseases, 301 East

17th Street, Room 1410, New York, NY 10003, USA.

E-mail:daria.crittenden@nyumc.org

Accepted for publication March 21, 2012.
Atherosclerosis, from plaque development to acute thrombosis, is an inflammatory process ${ }^{1}$. Within the atherosclerotic lesion, oxidized lipids induce the recruitment and activation of leukocytes (including macrophages and T cells), the uptake of lipids into macrophages, and the conversion of macrophages into foam cells ${ }^{2,3}$. Both modified lipids and cytokines secreted from recruited leukocytes induce expression of adhesion molecules on vascular endothelium, promoting further leukocyte adhesion and influx ${ }^{4,5,6}$. Cholesterol crystals have been shown to directly activate the NLRP3 inflammasome, driving production of interleukin $1 \beta(\mathrm{IL}-1 \beta)^{7}$. C-reactive protein (CRP) may also amplify the inflammatory/atherosclerotic process $^{8}$. Plaque instability is thought to arise in part from leukocyte secretion of metalloproteinases and other matrix-destroying enzymes ${ }^{9,10}$. Acute coronary syndrome results from plaque rupture and intravascular thrombus formation, a process requiring both activated tissue factor ${ }^{11}$ and the participation of neutrophils ${ }^{12,13,14}$. Indeed, there is growing evidence that neutrophils are involved in the pathogenesis of atherosclerosis at various stages ${ }^{15}$.

Clinical outcomes data support a role for inflammation in the pathogenesis of cardiovascular (CV) disease. Elevated 
CRP levels are associated with increased CV risk in a diverse range of clinical settings ${ }^{16,17,18}$. The presence of elevated levels of inflammatory markers prior to percutaneous coronary revascularization is associated with higher rates of periprocedural myocardial infarction (MI) and subsequent cardiac events ${ }^{19,20}$. In a prospective analysis of participants in the JUPITER trial, reduction of CRP by rosuvastatin correlated independently with reduced $\mathrm{CV}$ events ${ }^{21}$, probably through the statin's antiinflammatory effects ${ }^{22}$. In patients with rheumatoid arthritis, correction of the inflammatory state using anti-tumor necrosis factor (TNF) therapy is associated with reduced rates of adverse $\mathrm{CV}$ outcomes ${ }^{23}$. A recent systematic review suggests that absolute neutrophil counts correlate with outcome in patients with acute coronary syndromes and/or undergoing cardiac revascularization ${ }^{24}$.

Colchicine is an effective antiinflammatory agent, used primarily to treat familial Mediterranean fever and gout. At low doses $(0.5-0.6 \mathrm{mg}$ once or twice daily), colchicine is generally safe and well tolerated $25,26,27,28,29$. Colchicine's mechanisms of action are complex and not fully elucidated. It disrupts microtubule polymerization and interferes with multiple cell functions ${ }^{30,31}$. In the context of crystal-induced inflammation, colchicine has been shown to inhibit neutrophil cell mobility, activation (suppression of tyrosine phosphorylation and granule enzyme release), and generation of chemotactic signals ${ }^{32,33,34,35}$. Colchicine further modulates inflammatory cascades by increasing cAMP levels in leukocytes ${ }^{36,37,38}$. In macrophages, colchicine can inhibit activation of the NLRP3 inflammasome ${ }^{39}$. It may also inhibit TNF- $\alpha$ synthesis and downregulate TNF- $\alpha$ receptor expression in macrophages and endothelial cells ${ }^{40,41}$. Even at low doses, colchicine reduces the qualitative expression of the endothelial adhesion molecules such as E-selectin ${ }^{42,43,44}$.

Despite its ability to target cells that are involved in vascular inflammation, the effect of colchicine on CV disease has been evaluated only to a limited extent. Nidorf and Thompson reported that, in patients with stable coronary artery disease and elevated CRP, $0.5 \mathrm{mg}$ colchicine twice daily resulted in a 60\% decrease in CRP levels at 4 weeks, compared with control patients ${ }^{45}$. On the other hand, Raju, et al found no lowering of CRP in patients receiving 30 days of colchicine, $1 \mathrm{mg}$ daily, after MI or stroke ${ }^{46}$. Given the relative safety of colchicine, as well as its activity against cells implicated in plaque formation, rupture, and thrombosis, it would be desirable to know whether colchicine could be of benefit in preventing $\mathrm{CV}$ events.

Patients with gout typically have multiple comorbidities that increase their $\mathrm{CV}$ risk $^{47}$. Gout itself may be an independent risk factor for cardiac events and mortality ${ }^{48,49}$. Moreover, gout is a disease in which many patients routinely use colchicine. We therefore conducted a cross-sectional, hypothesis-generating study to assess the association between colchicine use and prevalence of MI in patients with gout.

\section{MATERIALS AND METHODS}

Our study was approved by the Institutional Review Board and Research and Development Committee of the New York Harbor Healthcare System of the U.S. Department of Veterans Affairs. Using the electronic medical record (EMR) of the New York Harbor Healthcare System (New York, Brooklyn, and Queens campus hospitals), we identified all patients with an International Classification of Diseases, 9th ed (ICD-9) code for gout (274.XX) who had at least 1 visit to the system between August 2007 and July 2008. (Among a smaller cohort of 575 patients included in this group, we previously reported that the use of an ICD-9 code diagnosis correlated well with a diagnosis of gout confirmed by American College of Rheumatology or other rigorous clinical criteria, with an accuracy of $\geq 80 \%$ in our patient population ${ }^{47}$.) For each patient, we used the physician-completed problem list to identify demographics, comorbidities, and outcomes documented at any time in the patient record before or during the enrollment period and up to 6 months after it ended. Where problem-list data were ambiguous (e.g., overlapping or conflicting information listed), patient status was confirmed by direct chart review. Values for items such as body mass index (BMI), blood pressure, and $\mathrm{CRP}$ represented the most recent data available for each category. Medication use was ascertained according to electronic pharmacy prescription record.

Patients with gout were separated into cohorts according to whether they had been treated with colchicine. Patients who had received colchicine according to pharmacy records of filled prescriptions were included in the colchicine group. The primary outcome was a diagnosis of MI, defined by physician coding (ICD-9 code 410.X). Secondary outcomes were death from any cause (according to death notes in the EMR during or after the enrollment year) and most recent CRP level. We analyzed the subjects further according to colchicine and allopurinol use (neither agent, allopurinol alone, colchicine alone, or both agents) for patient characteristics and outcomes. Statistical comparisons for continuous variables were calculated using Student's T test. Statistical comparisons for categorical variables were calculated using the chi-square test. Calculations were performed using InStat 3 ( GraphPad Software Inc.).

\section{RESULTS}

From among 40,107 patients actively registered in the EMR of the New York Harbor Healthcare System during the study period, we identified 1288 whose record included a diagnostic code for gout. Among the gout subjects, 576 had a history of colchicine use and 712 had no history of colchicine use (Figure 1).

Gout patients in the study had a mean age of 71.3 years and were overwhelmingly male (>99\%). Colchicine users and nonusers were similar in age, sex, BMI, ethnic distribution, and traditional risk factors for coronary artery disease (Table 1). Additionally, colchicine users and nonusers had similar serum urate levels, based on the most recent values available. In a subset analysis restricted to 1 of the 3 hospital sites ( $\mathrm{n}=$ $575)$, colchicine $(\mathrm{n}=236)$ and no-colchicine $(\mathrm{n}=339)$ groups also had similar nonsteroidal antiinflammatory drug, statin, and aspirin use (Table 1).

In contrast to the no-colchicine group, colchicine users had a decreased prevalence of MI (7 MI in the colchicine group vs 19 in the no-colchicine group) that was statistically significant (RR 0.46, $\mathrm{p}=0.03$; Table 2). Colchicine users also demonstrated a trend toward decreased all-cause mortality (23 deaths in the colchicine group vs 36 in the no-colchicine group; RR $0.76, p=0.18$ ), although this trend did not achieve statistical significance. Among patients for whom CRP data were avail- 


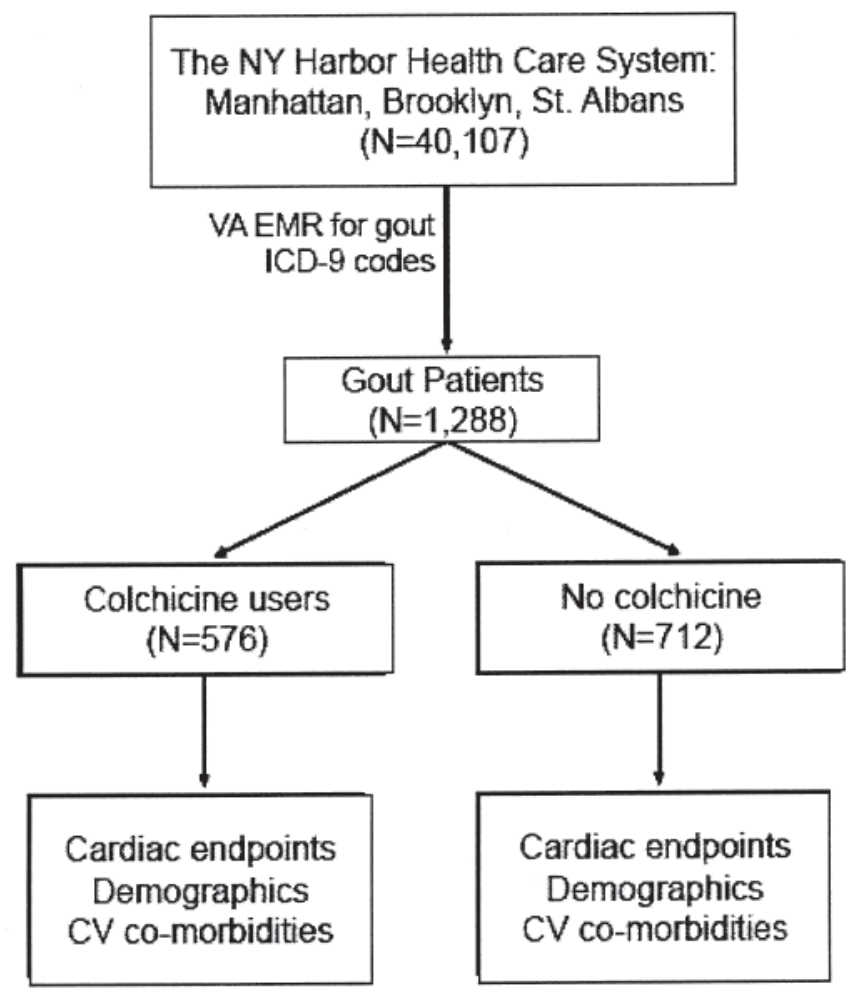

Figure 1. Study design and enrollment. CV: cardiovascular; VA: Department of Veterans Affairs; EMR: electronic medical records; ICD-9: International Classification of Diseases, 9th ed.

able, colchicine users $(n=135)$ had lower mean and median CRP levels than non-colchicine users $(n=85)$, but mean CRP differences also did not achieve statistical significance (mean CRP colchicine users vs nonusers, 2.5 vs $3.4 \mathrm{mg} / \mathrm{dl}$, respectively; $\mathrm{p}=0.24$; median CRP colchicine users vs non-users, $0.498 \mathrm{vs} 0.741 \mathrm{mg} / \mathrm{dl}$; Table 2).

Because the use of billing and EMR codes to identify MI and colchicine use may have intrinsic limitations, and because our cross-sectional study design might have identified patients whose colchicine use followed rather than preceded the MI events, we directly reviewed the charts of patients with coded MI for a more rigorous reanalysis. For this analysis, patients were considered to have MI only if the record showed evidence of cardiac enzyme elevation plus either ischemic symptoms, electrocardiographic changes, or imaging documentation of new focal cardiac defects, or a definitive note from a cardiologist confirming MI. Patients lacking sufficient documentation for a definitive assessment were removed from analysis; patients whose record definitively lacked these features were recategorized as having had no MI. Additionally, we confirmed whether the patients using colchicine had been taking the drug at the time of their MI event. Patients whose first colchicine use occurred after their MI event were recategorized as non-colchicine users, and patients whose colchicine use was found to be strictly on an as-needed basis for attacks were excluded. In this reanalysis, the difference between colchicine users/nonusers for MI events was even
Table 1. Comparison of all patients taking or not taking colchicine: demographics, cardiovascular risk factors, and medication use $(n=1288)$. Data are percentage affected or mean $\pm \mathrm{SD}$.

\begin{tabular}{|c|c|c|}
\hline Characteristic & $\begin{array}{l}\text { Colchicine } \\
\mathrm{n}=576\end{array}$ & $\begin{array}{c}\text { No Colchicine, } \\
n=712\end{array}$ \\
\hline Age, yrs & $71.3 \pm 11.8$ & $71.3+11.9$ \\
\hline \multicolumn{3}{|l|}{ Sex } \\
\hline Male & 99.6 & 99.2 \\
\hline Female & 0.4 & 0.8 \\
\hline \multicolumn{3}{|l|}{ Race/ethnicity } \\
\hline White & 48.2 & 50.9 \\
\hline Black & 38.3 & 32.7 \\
\hline Hispanic & 7.2 & 6.1 \\
\hline Pacific Islands & 1 & 0.8 \\
\hline Asian & 1.3 & 1.1 \\
\hline Not stated & 4.8 & 8.7 \\
\hline Body mass index & $29.5 \pm 5.6$ & $29.4 \pm 5.7$ \\
\hline Hypertension & 86.4 & 82.7 \\
\hline SBP, mm Hg & $129.5 \pm 19$ & $128.7 \pm 18.6$ \\
\hline $\mathrm{DBP}, \mathrm{mm} \mathrm{Hg}$ & $73.5 \pm 13$ & $72.7 \pm 13.1$ \\
\hline Diabetes & 29.3 & 29.3 \\
\hline HgbAlc, \% & $6.3 \pm 1.5$ & $6.4 \pm 2.5$ \\
\hline Hyperlipidemia & 63.9 & 64.2 \\
\hline $\mathrm{LDL}, \mathrm{mg} / \mathrm{dl}$ & $91.6 \pm 31.9$ & $91.6 \pm 26.6$ \\
\hline HDL, mg/dl & $46.8 \pm 15.3$ & $47.8 \pm 14.9$ \\
\hline Kidney disease & 34.7 & 31.9 \\
\hline $\mathrm{eGFR}, \mathrm{ml} / \mathrm{min}$ & $68.6 \pm 26.2$ & $67.5 \pm 26.6$ \\
\hline Serum creatinine, $\mathrm{mg} / \mathrm{dl}$ & $1.4 \pm 0.8$ & $1.5 \pm 1.2$ \\
\hline Peripheral vascular disease & 7.1 & 7.6 \\
\hline Coronary artery disease & 30.4 & 27.8 \\
\hline Congestive heart failure & 11.7 & 10.4 \\
\hline Coronary bypass & 4.2 & 4.8 \\
\hline Current smoker & 11.7 & 10.5 \\
\hline Serum urate & $7.8 \pm 2.1$ & $7.5 \pm 2.1$ \\
\hline Statin use* & 57.2 & 57.5 \\
\hline NSAID use* & 21.6 & 17.1 \\
\hline Aspirin use* & 41.1 & 41 \\
\hline Allopurinol use & 46.9 & 40.7 \\
\hline
\end{tabular}

* Subset analysis of 236 colchicine users and 339 nonusers. LDL: low-density lipoprotein; HDL: high-density lipoprotein; eGFR: estimated glomerular filtration rate; SBP: systolic blood pressure; DBP: diastolic blood pressure; NSAID: nonsteroidal antiinflammatory drugs.

more prominent than in the original cross-sectional analysis: colchicine users had an MI prevalence of 0.0017 versus an MI prevalence of 0.02 for non-colchicine users (RR $0.08, \mathrm{p}=$ 0.0015).

In an analysis of our patient population according to allopurinol use, we identified 306 patients who took colchicine without allopurinol, 289 who took allopurinol without colchicine, 270 who took both, and 423 patients taking neither agent. Patients in these groups were again similar in terms of demographics and cardiac risk factors, with the exception of chronic kidney disease, which was markedly lower in the allopurinol-use groups (Table 3). Compared with patients who used neither colchicine nor allopurinol, patients who used allopurinol alone demonstrated a trend toward decreased prevalence of MI that did not achieve statistical significance Personal non-commercial use only. The Journal of Rheumatology Copyright $\odot$ 2012. All rights reserved. 
Table 2. Myocardial infarction (MI) and death rates, and most recent C-reactive protein (CRP) levels in patients with gout taking or not taking colchicine $(\mathrm{n}=1288)$.

\begin{tabular}{lcccc}
\hline Outcome & $\begin{array}{c}\text { Colchicine, } \\
\mathrm{n}=576\end{array}$ & $\begin{array}{c}\text { No Colchicine, } \\
\mathrm{n}=712\end{array}$ & $\mathrm{p}$ & Relative Risk \\
\hline MI, \% & 1.2 & 2.6 & 0.03 & 0.46 \\
Death, \% & 3.9 & 5.1 & 0.18 & 0.76 \\
CRP, mean $\pm \mathrm{SD} \mathrm{mg/dl}$ & $2.5 \pm 4.6$ & $3.4 \pm 5.6$ & 0.24 & - \\
\hline
\end{tabular}

Table 3. Demographics, cardiovascular risk factors, and medication use in patients taking neither drug, allopurinol, colchicine, or both agents $(n=1288)$. Data are percentage affected or mean $\pm S D$.

\begin{tabular}{|c|c|c|c|c|}
\hline Characteristic & $\begin{array}{c}\text { Neither Drug, } \\
n=423\end{array}$ & $\begin{array}{c}\text { Allopurinol, } \\
\mathrm{n}=289\end{array}$ & $\begin{array}{l}\text { Colchicine, } \\
\mathrm{n}=306\end{array}$ & $\begin{array}{c}\text { Both, } \\
\mathrm{n}=270\end{array}$ \\
\hline Age, yrs & $72.3 \pm 11.2$ & $70.5 \pm 12.8$ & $71.0 \pm 4.5$ & $71.8 \pm 11.5$ \\
\hline \multicolumn{5}{|l|}{ Sex } \\
\hline Male & 99.0 & 99.0 & 99.4 & 100 \\
\hline Female & 1.0 & 1.0 & 0.6 & 0 \\
\hline \multicolumn{5}{|l|}{ Race/ethnicity } \\
\hline White & 52.8 & 46.9 & 47.1 & 48.5 \\
\hline Black & 32.7 & 32.1 & 35.6 & 41.2 \\
\hline Hispanic & 5.9 & 6.2 & 12.1 & 4.4 \\
\hline Pacific Islands & 0.7 & 1.0 & 1.0 & 1.1 \\
\hline Asian & 1.7 & 0.3 & 1.6 & 1.1 \\
\hline Not stated & 6.2 & 12.4 & 3.6 & 3.7 \\
\hline Body mass index & $29.0 \pm 5.5$ & $30.0 \pm 6.0$ & $29.1 \pm 1.1$ & $29.9 \pm 5.8$ \\
\hline Hypertension & 86.5 & 77.0 & 89.5 & 83.0 \\
\hline $\mathrm{SBP}, \mathrm{mm} / \mathrm{Hg}$ & $126.9 \pm 17.3$ & $131.3 \pm 19.9$ & $128.5 \pm 11.5$ & $130 \pm 18.3$ \\
\hline $\mathrm{DBP}, \mathrm{mm} / \mathrm{Hg}$ & $70.9 \pm 12.9$ & $75.4 \pm 13.0$ & $72.8 \pm 8.0$ & $74.3 \pm 13.3$ \\
\hline Diabetes & 29.4 & 29.3 & 29.0 & 29.6 \\
\hline HgbAlc (\%) & $6.5 \pm 4.4$ & $6.46 \pm 1.2$ & $6.34 \pm 1.9$ & $6.3 \pm 1.1$ \\
\hline Hyperlipidemia & 64.7 & 63.4 & 61.4 & 66.7 \\
\hline $\mathrm{LDL}, \mathrm{mg} / \mathrm{dl}$ & $90.0 \pm 33.3$ & $93.9 \pm 32.8$ & $89.6 \pm 9.5$ & $93.8 \pm 33.8$ \\
\hline $\mathrm{HDL}, \mathrm{mg} / \mathrm{dl}$ & $47.6 \pm 13.7$ & $48.1 \pm 16.5$ & $47.2 \pm 4.5$ & $46.3 \pm 17.0$ \\
\hline Kidney disease & 42.9 & 15.9 & 41.8 & 26.7 \\
\hline $\mathrm{eGFR}, \mathrm{ml} / \mathrm{min}$ & $66.0 \pm 29.6$ & $71.8 \pm 27.5$ & $69.2 \pm 25.0$ & $68.0 \pm 28.5$ \\
\hline Serum creatinine, mg/dl & $1.5 \pm 1.0$ & $1.5 \pm 1.4$ & $1.3 \pm 0.5$ & $1.5 \pm 0.9$ \\
\hline Peripheral vascular disease & 7.1 & 8.3 & 6.5 & 7.8 \\
\hline Coronary artery disease & 33.2 & 20.0 & 34.0 & 26.3 \\
\hline Congestive heart failure & 10.0 & 11.7 & 9.2 & 14.4 \\
\hline Coronary bypass & 4.0 & 5.9 & 2.6 & 5.9 \\
\hline Current smoker & 12.6 & 7.3 & 16 & 7.0 \\
\hline Serum urate & $7.5 \pm 2.1$ & $7.5 \pm 2.0$ & $7.7 \pm 0.25$ & $7.8 \pm 2.2$ \\
\hline Statin use* & 58.1 & 65.1 & 52.0 & 16.2 \\
\hline NSAID use* & 19.4 & 17.1 & 23.2 & 52.3 \\
\hline Aspirin use* & 36.6 & 42.5 & 45.6 & 41.4 \\
\hline
\end{tabular}

* Subset analysis of 575 patients from a single institution: 193 prescribed neither allopurinol nor colchicine, 146 prescribed allopurinol only, 125 prescribed colchicine only, 111 prescribed both drugs. LDL: low-density lipoprotein; HDL: high-density lipoprotein; eGFR: estimated glomerular filtration rate; SBP: systolic blood pressure; DBP: diastolic blood pressure; NSAID: nonsteroidal antiinflammatory drugs.

(allopurinol vs no drug $2.08 \%$ vs $3.08 \%$, respectively; RR $0.68, \mathrm{p}=0.21)$. In contrast, subjects who used colchicine alone demonstrated a statistically significant decrease in MI prevalence (colchicine alone vs no drug $0.6 \%$ vs $3.08 \%$; RR $0.19, \mathrm{p}=0.01$; Figure 2). Use of both colchicine and allopurinol also resulted in a decrease in MI relative to no drug $(1.1 \%$ vs $3.08 \%$; RR $0.35, \mathrm{p}=0.046)$. The effect of colchicine together with allopurinol for this outcome did not differ significantly from that of colchicine alone $(\mathrm{p}=0.27)$. Colchicine patients again demonstrated a nonsignificant trend toward reduced all-cause mortality (colchicine alone vs no drug $4.3 \%$ vs $5.9 \%$; RR $0.73, \mathrm{p}=0.16$ ).

\section{DISCUSSION}

To our knowledge, ours is the first study correlating the use of colchicine with decreased acute coronary events. In our study, patients with gout who used colchicine had a significantly lower prevalence of MI than those who did not use colchicine. 


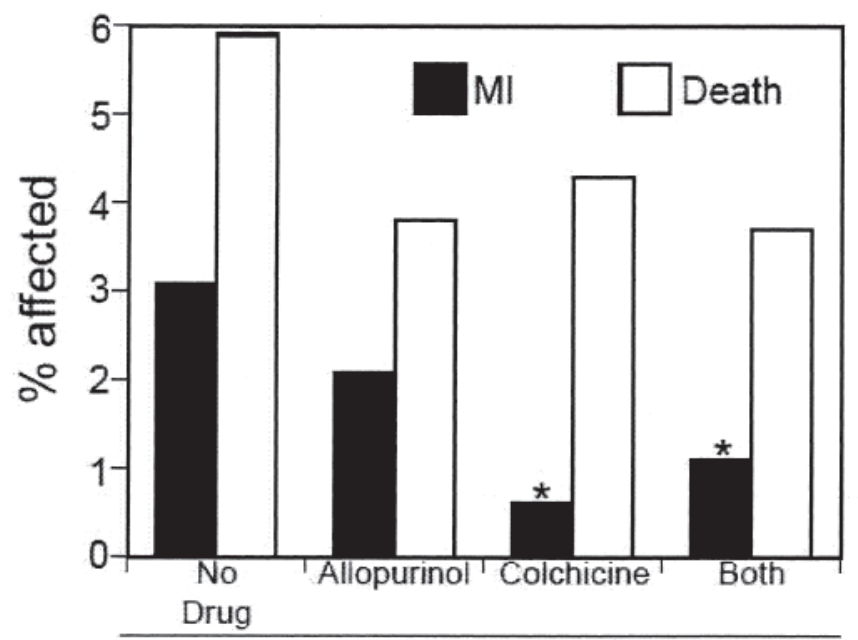

Treatment condition

Figure 2. Prevalence of diagnosis of myocardial infarction (MI) and death in gout patients using neither allopurinol nor colchicine, allopurinol alone, colchicine alone, or both agents. ${ }^{*} \mathrm{p}<0.05$ vs patients using neither agent.

We observed no differences in demographics or traditional cardiac risk factors to account for the differences in outcomes between the colchicine and no-colchicine groups.

The fact that colchicine users had similar prevalence of diagnosis of coronary artery disease, peripheral vascular disease, etc., suggests that any possible colchicine effect may be more likely to relate to effects on acute coronary syndrome, rather than to the development of atherosclerosis.

While our data do not permit us to identify or confirm a mechanism of colchicine action to explain a possible cardioprotective effect, it is plausible that colchicine might act to support plaque stability and/or reduce the effects of plaque rupture by blocking macrophage activation, endothelial activation, and neutrophil influx and activation, or a combination of all 3. Although colchicine has not been shown to have strong effects on platelets ${ }^{46}$, it is not established whether the ability of colchicine to alter vascular and cellular expression of adhesion molecules could influence platelet adhesion to modulate thrombus formation.

In keeping with the findings of Nidorf and Thompson ${ }^{45}$, we observed a trend toward reduced CRP levels in the patients who used colchicine, although this reduction did not achieve statistical significance. Factors limiting our ability to assess differences in CRP include the fact that not all subjects had CRP levels available for analysis. Additionally, some of the CRP tests reviewed in our study were ordered in the midst of acute gout attacks. Consequently, some CRP values were extremely high, and the range of CRP values within each patient group was wide. Although patients who used colchicine had an overall reduced all-cause mortality, these trends also did not achieve statistical significance, possibly as a result of our relatively small sample size.

Hyperuricemia has been proposed as an independent risk factor for $\mathrm{CV}$ disease, and recent studies suggest that the use of urate-lowering agents such as xanthine oxidase inhibitors is associated with reduction in $\mathrm{CV}$ risk, including $\mathrm{MI}^{50,51,52,53,54}$. In our analysis of subjects according to allopurinol and colchicine use (neither agent, allopurinol alone, colchicine alone, or both agents), patient demographics and traditional risk factors were similar across the 4 groups, with the exception of lower prevalence of chronic kidney disease among allopurinol users, probably relating to primary care physicians' reluctance to prescribe allopurinol in the setting of renal insufficiency 55,56 . Overall, use of allopurinol did not appear to be confounding the reduced prevalence of MI observed in the colchicine group because (1) users of allopurinol alone did not have a significantly lower prevalence of MI compared to patients taking neither drug, and (2) patients taking colchicine with or without allopurinol had fewer MI relative to patients taking neither drug.

Our study has both strengths and limitations. Although our cohort was relatively large, it is small in comparison to studies using epidemiologic or insurance databases, which may have limited our ability to achieve statistical significance for modest drug effects. Our use of a gout population allowed us to study colchicine associations in a patient cohort that both is at increased CV risk and has a high rate of colchicine use; on the other hand, in this cohort it may not be possible to distinguish direct $\mathrm{CV}$ effects of colchicine from those that relate to gout treatment per se. Further, while we previously reported an accuracy of $80 \%$ for confirmed gout diagnosis among patients with an ICD-9 code for gout ${ }^{47}$, we note that Malik, et al found a lower correlation between electronic codes and confirmation of diagnosis in a VA population ${ }^{57}$, and acknowledge that use of ICD-9 codes may be a limitation in our study. The cross-sectional design of our study, while useful for a pilot project, also has inherent limitations. Given the study design, we were unable to examine treating physicians' reasons for using or not using colchicine in a given patient, introducing the possibility of confounding by indication; however, as noted, the 2 groups had no significant differences in established cardiac risk factors (including renal function), potentially mitigating this limitation. Importantly, the retrospective, cross-sectional approach did not permit us to analyze the chronologic relationship between duration of gout, start and duration of colchicine use, and occurrence of MI. Thus, our observed association between colchicine use and MI prevalence must be considered hypothesis-generating rather than definitive, regarding any question of cause and effect. We are currently developing additional, cohort-based, non-cross-sectional studies to address these limitations.

There is growing interest in antiinflammatory strategies as a means of reducing CV morbidity and mortality. Studies are under way to evaluate whether methotrexate and IL-1ß antagonists reduce $\mathrm{CV}$ events in patients with coronary artery disease $^{58,59}$. Our data suggest that colchicine use is associated with a reduced risk of MI in patients with gout. This observation provides a rationale for further studies to investigate this Personal non-commercial use only. The Journal of Rheumatology Copyright (c) 2012. All rights reserved. 
association, perhaps including prospective studies to evaluate the effects of colchicine on $\mathrm{CV}$ events in high-risk patients with or without gout. Given the relatively benign side effect profile of low-dose colchicine in most clinical settings, colchicine could provide a useful addition to the resources for prevention or treatment of $\mathrm{CV}$ disease.

\section{ACKNOWLEDGMENT}

The authors thank Drs. Gerald Weissmann and Steven B. Abramson for helpful suggestions, and Drs. Kristen Lee and William O'Brien for participating in the initial data collection for this study.

\section{REFERENCES}

1. Hansson GK. Inflammation, atherosclerosis, and coronary artery disease. N Engl J Med 2005;352:1685-95.

2. Stemme S, Faber B, Holm J, Wiklund O, Witztum JL, Hansson GK. $\mathrm{T}$ lymphocytes from human atherosclerotic plaques recognize oxidized low density lipoprotein. Proc Natl Acad Sci USA 1995;92:3893-7.

3. Miller YI, Choi SH, Fang L, Harkewicz R. Toll-like receptor-4 and lipoprotein accumulation in macrophages. Trends Cardiovasc Med 2009;19:227-32.

4. Bouhlel MA, Derudas B, Rigamonti E, Dievart R, Brozek J, Haulon $\mathrm{S}$, et al. PPAR-gamma activation primes human monocytes into alternative M2 macrophages with anti-inflammatory properties. Cell Metab 2007;6:137-43.

5. Badimon L, Storey RF, Vilahur G. Update on lipids, inflammation and atherothrombosis. Thromb Haemost 2011;105 Suppl 1:S34-42.

6. Eriksson EE, Xie X, Werr J, Thoren P, Lindbom L. Importance of primary capture and L-selectin-dependent secondary capture in leukocyte accumulation in inflammation and atherosclerosis in vivo. J Exp Med 2001;194:205-18.

7. Rajamaki K, Lappalainen J, Oorni K, Valimaki E, Matikainen S, Kovanen PT, et al. Cholesterol crystals activate the NLRP3 inflammasome in human macrophages: A novel link between cholesterol metabolism and inflammation. PLoS One 2010;5:e11765.

8. Yeh ET, Anderson HV, Pasceri V, Willerson JT. C-reactive protein: Linking inflammation to cardiovascular complications. Circulation 2001;104:974-5.

9. Cybulsky MI, Gimbrone MA Jr. Endothelial expression of a mononuclear leukocyte adhesion molecule during atherogenesis. Science 1991;251:788-91.

10. Ketelhuth DF, Back M. The role of matrix metalloproteinases in atherothrombosis. Curr Atheroscler Rep 2011;13:162-9.

11. Owens AP 3rd, Mackman N. Tissue factor and thrombosis: The clot starts here. Thromb Haemost 2010;104:432-9.

12. Perrin J, Morlon L, Vigneron C, Marchand-Arvier M. Influence of polymorphonuclear leukocytes on the plasma clot formation as evaluated by thromboelastometry (ROTEM). Thromb Res 2008;121:647-52.

13. Fuchs TA, Brill A, Duerschmied D, Schatzberg D, Monestier M, Myers DD Jr, et al. Extracellular DNA traps promote thrombosis. Proc Natl Acad Sci USA 2010;107:15880-5.

14. Massberg S, Grahl L, von Bruehl ML, Manukyan D, Pfeiler S, Goosmann C, et al. Reciprocal coupling of coagulation and innate immunity via neutrophil serine proteases. Nat Med 2010;16:887-96.

15. Baetta R, Corsini A. Role of polymorphonuclear neutrophils in atherosclerosis: Current state and future perspectives. Atherosclerosis 2010;210:1-13.

16. Abd TT, Eapen DJ, Bajpai A, Goyal A, Dollar A, Sperling L. The role of C-reactive protein as a risk predictor of coronary atherosclerosis: Implications from the JUPITER trial. Curr Atheroscler Rep 2011;13:154-61.

17. Ridker PM, Hennekens CH, Buring JE, Rifai N. C-reactive protein and other markers of inflammation in the prediction of cardiovascular disease in women. N Engl J Med 2000;342:836-43.

18. Haverkate F, Thompson SG, Pyke SD, Gallimore JR, Pepys MB. Production of C-reactive protein and risk of coronary events in stable and unstable angina. European Concerted Action on Thrombosis and Disabilities Angina Pectoris Study Group. Lancet 1997;349:462-6.

19. Chan AW, Bhatt DL, Chew DP, Reginelli J, Schneider JP, Topol EJ, et al. Relation of inflammation and benefit of statins after percutaneous coronary interventions. Circulation 2003;107:1750-6.

20. Patti G, Di Sciascio G, D'Ambrosio A, Dicuonzo G, Abbate A, Dobrina A. Prognostic value of interleukin-1 receptor antagonist in patients undergoing percutaneous coronary intervention. Am J Cardiol 2002;89:372-6.

21. Ridker PM, Danielson E, Fonseca FA, Genest J, Gotto AM Jr, Kastelein JJ, et al. Reduction in C-reactive protein and LDL cholesterol and cardiovascular event rates after initiation of rosuvastatin: A prospective study of the JUPITER trial. Lancet 2009;373:1175-82.

22. Abeles AM, Pillinger MH. Statins as antiinflammatory and immunomodulatory agents: A future in rheumatologic therapy? Arthritis Rheum 2006;54:393-407.

23. Greenberg JD, Kremer JM, Curtis JR, Hochberg MC, Reed G, Tsao $\mathrm{P}$, et al. Tumour necrosis factor antagonist use and associated risk reduction of cardiovascular events among patients with rheumatoid arthritis. Ann Rheum Dis 2011;70:576-82.

24. Guasti L, Dentali F, Castiglioni L, Maroni L, Marino F, Squizzato A, et al. Neutrophils and clinical outcomes in patients with acute coronary syndromes and/or cardiac revascularisation. A systematic review on more than 34,000 subjects. Thromb Haemost 2011;106:591-9.

25. Yang LP. Oral colchicine (Colcrys) in the treatment and prophylaxis of gout. Drugs 2010;70:1603-13.

26. Kallinich T, Haffner D, Niehues T, Huss K, Lainka E, Neudorf U, et al. Colchicine use in children and adolescents with familial Mediterranean fever: Literature review and consensus statement. Pediatrics 2007;119:e474-83.

27. Terkeltaub RA, Furst DE, Bennett K, Kook KA, Crockett RS, Davis MW. High versus low dosing of oral colchicine for early acute gout flare: Twenty-four-hour outcome of the first multicenter, randomized, double-blind, placebo-controlled, parallel-group, dose-comparison colchicine study. Arthritis Rheum 2010;62:1060-8.

28. Borstad GC, Bryant LR, Abel MP, Scroggie DA, Harris MD, Alloway JA. Colchicine for prophylaxis of acute flares when initiating allopurinol for chronic gouty arthritis. J Rheumatol 2004;31:2429-32.

29. Kershenobich D, Vargas F, Garcia-Tsao G, Perez Tamayo R, Gent M, Rojkind M. Colchicine in the treatment of cirrhosis of the liver. N Engl J Med 1988;318:1709-13.

30. Nuki G. Colchicine: Its mechanism of action and efficacy in crystal-induced inflammation. Curr Rheumatol Rep 2008;10:218-27.

31. Molad Y. Update on colchicine and its mechanism of action. Curr Rheumatol Rep 2002;4:252-6.

32. Caner JE. Colchicine inhibition of chemotaxis. Arthritis Rheum 1965;8:757-64

33. Wright DG, Malawista SE. Mobilization and extracellular release of granular enzymes from human leukocytes during phagocytosis: Inhibition by colchicine and cortisol but not by salicylate. Arthritis Rheum 1973;16:749-58.

34. Phelps P. Polymorphonuclear leukocyte motility in vitro. IV. Colchicine inhibition of chemotactic activity formation after 
phagocytosis of urate crystals. Arthritis Rheum 1970;13:1-9.

35. Roberge CJ, Gaudry M, de Medicis R, Lussier A, Poubelle PE, Naccache PH. Crystal-induced neutrophil activation. IV. Specific inhibition of tyrosine phosphorylation by colchicine. J Clin Invest 1993;92:1722-9.

36. Leiber D, Jasper JR, Alousi AA, Martin J, Bernstein D, Insel PA. Alteration in Gs-mediated signal transduction in S49 lymphoma cells treated with inhibitors of microtubules. J Biol Chem 1993;268:3833-7.

37. Higgs GA, Harvey EA, Ferreira SH, Vane JR. The effects of antiinflammatory drugs on the production of prostaglandins in vivo. Adv Prostaglandin Thromboxane Res 1976;1:105-10.

38. Rudolph SA, Greengard P, Malawista SE. Effects of colchicine on cyclic AMP levels in human leukocytes. Proc Natl Acad Sci USA 1977;74:3404-8.

39. Martinon F, Petrilli V, Mayor A, Tardivel A, Tschopp J. Gout-associated uric acid crystals activate the NALP3 inflammasome. Nature 2006;440:237-41.

40. Li Z, Davis GS, Mohr C, Nain M, Gemsa D. Inhibition of LPS-induced tumor necrosis factor-alpha production by colchicine and other microtubule disrupting drugs. Immunobiology 1996;195:624-39

41. Ding AH, Porteu F, Sanchez E, Nathan CF. Downregulation of tumor necrosis factor receptors on macrophages and endothelial cells by microtubule depolymerizing agents. J Exp Med 1990;171:715-27.

42. Cronstein BN, Molad Y, Reibman J, Balakhane E, Levin RI, Weissmann G. Colchicine alters the quantitative and qualitative display of selectins on endothelial cells and neutrophils. J Clin Invest 1995;96:994-1002.

43. Perico N, Ostermann D, Bontempeill M, Morigi M, Amuchastegui $\mathrm{CS}$, Zoja $\mathrm{C}$, et al. Colchicine interferes with L-selectin and leukocyte function-associated antigen-1 expression on human $\mathrm{T}$ lymphocytes and inhibits T cell activation. J Am Soc Nephrol 1996;7:594-601.

44. Kiraz S, Ertenli I, Arici M, Calguneri M, Haznedaroglu I, Celik I, et al. Effects of colchicine on inflammatory cytokines and selectins in familial Mediterranean fever. Clin Exp Rheumatol 1998;16:721-4.

45. Nidorf M, Thompson PL. Effect of colchicine ( $0.5 \mathrm{mg}$ twice daily) on high-sensitivity C-reactive protein independent of aspirin and atorvastatin in patients with stable coronary artery disease. Am J Cardiol 2007;99:805-7.

46. Raju NC, Yi Q, Nidorf M, Fagel ND, Hiralal R, Eikelboom JW Effect of colchicine compared with placebo on high sensitivity C-reactive protein in patients with acute coronary syndrome or acute stroke: A pilot randomized controlled trial. J Thromb Thrombolysis 2012;33:88-94.
47. Keenan RT, O'Brien WR, Lee KH, Crittenden DB, Fisher MC, Goldfarb DS, et al. Prevalence of contraindications and prescription of pharmacologic therapies for gout. Am J Med 2011;124:155-63.

48. Choi HK, Curhan G. Independent impact of gout on mortality and risk for coronary heart disease. Circulation 2007;116:894-900.

49. Krishnan E, Baker JF, Furst DE, Schumacher HR. Gout and the risk of acute myocardial infarction. Arthritis Rheum 2006;54:2688-96.

50. Wei L, Mackenzie IS, Chen Y, Struthers AD, MacDonald TM. Impact of allopurinol use on urate concentration and cardiovascular outcome. Br J Clin Pharmacol 2011;71:600-7.

51. Jiunn-Horng Chen W-HP. Effects of urate lowering therapy on cardiovascular mortality: A Taiwanese cohort study [abstract]. Arthritis Rheum 2010;62 Suppl:S872-3.

52. Rentoukas E, Tsarouhas K, Tsitsimpikou C, Lazaros G, Deftereos S, Vavetsi S. The prognostic impact of allopurinol in patients with acute myocardial infarction undergoing primary percutaneous coronary intervention. Int J Cardiol 2010;145:257-8.

53. Goicoechea M, de Vinuesa SG, Verdalles U, Ruiz-Caro C, Ampuero $\mathrm{J}$, Rincon A, et al. Effect of allopurinol in chronic kidney disease progression and cardiovascular risk. Clin J Am Soc Nephrol 2010;5:1388-93.

54. Luk AJ, Levin GP, Moore EE, Zhou XH, Kestenbaum BR, Choi HK. Allopurinol and mortality in hyperuricaemic patients. Rheumatology 2009;48:804-6.

55. Stamp LK, O’Donnell JL, Zhang M, James J, Frampton C, Barclay ML, et al. Using allopurinol above the dose based on creatinine clearance is effective and safe in patients with chronic gout, including those with renal impairment. Arthritis Rheum 2011;63:412-21.

56. Abeles AM, Pillinger MH. Allopurinol in renal insufficiency: A reappraisal. Rheumatology: Commentaries \& Controversies. 26 Aug 2011. [Internet. Accessed April 19, 2012.] Available from: http://www.lettertoeditor.org/article/show/110010

57. Malik A, Dinnella JE, Kwoh CK, Schumacher HR. Poor validation of medical record ICD-9 diagnoses of gout in a Veterans Affairs database. J Rheumatol 2009;36:1283-6.

58. Ridker PM. Testing the inflammatory hypothesis of atherothrombosis: Scientific rationale for the cardiovascular inflammation reduction trial (CIRT). J Thromb Haemost 2009;7 Suppl 1:332-9.

59. Libby P, Ridker PM, Hansson GK. Progress and challenges in translating the biology of atherosclerosis. Nature 2011;473:317-25. 